\title{
Mentally Challenged Children in Africa: Victims of Sexual Abuse
}

\author{
Jabulani G. Kheswa \\ Department of Psychology, University of Fort Hare, Private Bag X1314, Alice, 5700, South Africa. \\ Email: jkheswa@ufh.ac.za
}

\section{Doi:10.5901/mjss.2014.v5n27p959}

\begin{abstract}
The rate of sexual victimization of mentally retarded children is alarming and it goes unnoticed because the perpetrators could be parents, step- parents, relatives, well-respected individuals by family members, neighbours and educators. Drawing from labelling theory that the mentally retarded have low IQ, majority of perpetrators tend not to get arrested because of lack of evidence. Research indicates that educators struggle to identify the psychological, behavioural and physical symptoms of sexual abuse owing to their limited training. Having employed systematic review as methodology, this research study found that mentally retarded children are prone to HIVIAIDS, PTSD and feelings of helplessness owing to uninvolvement of parents, dysfunctional communities, poverty and their inability to differentiate between abuse and affection. Based on the findings, the recommendations are that: (1) extensive training for professionals, families and community members be executed to protect children with intellectual disability. Furthermore, the rights of the mentally retarded children must be respected in the court of law when reporting sexual abuse.
\end{abstract}

Keywords: sexual abuse; mental retardation; stigma; HIV/AIDS

\section{Introduction}

Mentally retarded or disabled people generally remain isolated and stigmatised despite the fact that in the Chapter 2 of the Constitution of the Republic of South Africa Act 106 of 1996, everyone regardless of disability, race, culture and gender, is entitled to fair treatment and equal opportunities (Burns, 2011; Donohue, Bornman \& Granlund, 2014). They are accorded far less social status in most societies and their behaviour is not tolerated (Mukolo, Heflinger \& Wallston, 2010) and this impact negatively on the mental well-being of their caregivers. For some children, mental retardation leads them to suffer from depression or anxiety because at school, their educators reject them (Louw \& Louw, 2007). In this article, mental retardation and its types will be defined and identified respectively. Furthermore, the causal factors of mental retardation,(e.g. biological and environmental) will be explored. Literature on sexual abuse of children with mental retardation will be discussed with the aim to call for the urgent intervention of the legal system, social workers, educators and community members in dealing with the perpetrators of child molesters.

\subsection{Mental retardation}

Mental retardation is a disorder found in the DSM IV- TR and refers to sub-average intellectual functioning (IQ below 70) and it onsets before the age of 18 . Children with mental retardation show cognitive impairments from early infancy such as showing limited verbal expression and poor self- regulation (an ability to look after oneself without the help of others) (Swart, de la Rey, Duncan \& Townsend \& O'Neil 2011). Concurrent deficits which may be manifested are in the areas of home-living, social or interpersonal skills, the use of community resources, self-direction, functional academic skills, work, leisure, health, and safety (Frumkin, 2003). Mental retardation is classified into four categories owing to its severity, namely; mild mental retardation, moderate mental retardation, severe mental retardation and profound mental retardation. Children with mild mental retardation have IQ level of 55-70, are in majority (89\%) in South Africa and often display small delays in cognitive development during preschool years (Louw \& Louw, 2007). They are educable and may acquire academic skills up to approximately Grade 6. A significant proportion of them manage to reach college provided their environments are affluent with resources including educators specially trained for inclusive education. When reaching adulthood, they successfully adapt to their environment and achieve vocational skills under the guidance and support of others (Nolen-Hoeksema, 2008).

According to Louw and Louw (2007) moderate mental retarded children have an IQ level between 35 and 50, and they are relatively semi- independent. They often have difficulty recognizing social conventions such as appropriate 
humor or dress, which interferes with peer relationships. According to Papalia, Olds and Feldman (2009) such children may attain up to Grade 4 and depend on their families for support. Children with severe mental retardation have limited speech because their IQ ranges from 25 to 40 . They speak in two- or three -word sentences. When playing with toys, they lose concentration and often fail to integrate or coordinate them owing to their deficts in motor development. When reaching adulthood, they may feed themselves with spoons and dress if their clothes are not complicated with many buttons. They cannot travel a long distance on their own or cook for themselves though they may be able to learn some unskilled labour such as cleaning the dishes and sweeping the floor ( Nolen-Hoeksema, 2008).

As compared to the three sub-types mentioned above, profound mental retardation requires full-time custodial care because children falling into this category suffer from frequent illnesses. Their speech is very little if not mute. They are not educable as their IQ scores are below 25 (Papalia et al., 2009). Nolen-Hoeksema, (2008) found out that such children have a shorter life- expectancy span than normal people. During early childhood they display considerable impairments in sensorimotor functioning; for example, at the age of 4 or 5 , their responsiveness is similar to that of a 1 year child (Passer, Smith, Holt, Bremmer, Sutherland \& Vliek, 2009).

\subsection{Causal factors of mental retardation}

Biologically, there are many factors which may contribute to mental retardation. Nolen-Hoeksema, (2008) outlined that when pregnant mothers are subject to nutritional deficiencies from poor eating habits, including attempts to lose weight through dieting, skipping meals, food faddism snacking, and consumption of fast food, they may be at risk of giving birth to mentally retarded children. Owing to lack of nutritional food such as B complex vitamins, Selenium folic acid and proteins giving birth to a child with IQ below 70, deficits in motor development and increases impulsivity. In addition, Weiten (2011) found out that due to contaminated milk which lacks nutrients, children may have conditions such as cerebral epilepsy, poor eye -hand coordination, deafness and autism.

According to Louw and Louw (2007) exposure to substance abuse such as drinking alcohol and taking drugs during pregnancy, may contribute to experiencing complications during labour and lead to mental retardation. It is worth realizing that when a pregnant woman drinks alcohol, she feeds the fetus as well. For that reason, Nolen-Hoeksema (2008) asserts that Down syndrome is inevitable. Down syndrome is a condition characterized by distinctive physical deformities such as slanted eyes, stubby limbs, small nose, round and flat faces, slightly protruding lips and tongues (Nolen-Hoeksema, 2008). Children with Down syndrome have delays in speech development, poor motor skills, and limitation in memory and cognition. When pregnant mothers live in cohabitating families, where there are urbanisationrelated challenges such as poor quality housing conditions, inadequate and limited access to health care, and education, greater is the likelihood of not attending clinics for monitoring prenatal developments (Leinonen, Solantaus \& Punamaki, 2003). Furthermore, when there is domestic violence in the family, emotional distress experienced by a pregnant woman associated as a result of physical abuse may cause a variety of physiological deformities such as deafness, cardiac abnormalities and/or mental retardation to the infants, including prematurity, hypoxia low birthweight and intracranial haemorrhage (Nolen-Hoeksema, 2008).

\subsection{Challenges faced by mentally retarded children}

\subsubsection{Neglect}

Care settings of mentally retarded children are often segregated and characterized by violence, torture, inadequate nutrition and grossly inadequate sanitation (Hunt \& Mesquita, 2006) despite full qualification of being beneficiaries of social grants received from the government. In Chongwe village, Zambia, mentally retarded children with epilepsy will be stopped to attend school when experiencing seizures. Due to lack of knowledge, educators would not care for them because of the perception that epilepsy is contagious (Fleming, Groce, Ngulube, Mindes \& Kiessel, 2010). By letting the mentally retarded children stay at home with no skills to protect themselves against abuse, these vulnerable group becomes susceptible to HIVIAIDS especially if their caregivers lack affection towards them, consume alcohol, are financially poor and illiterate. It is time that the human rights (i.e. right to HIVIAIDS knowledge, right to accessibility to health care) of this marginalised group of children are respected although the ostracism continues to compound even at international level. For example, at the International AIDS conference held in Washington in 2012, issues which concern the abduction, neglect and sexual abuse of mental challenged children were never addressed (IDDC, 2012). Is it because they are not economically productive? Secondly, what do the social workers do when the place of safety for these children is a fertile ground for exploitation and neglect? 


\subsubsection{Stigma and discrimination}

Stigma refers to the attitudes and beliefs that motivate individuals to fear reject and avoid those who are labelled, diagnosed or perceived to have mental illnesses. Based on the influence of Goffman's work, stigma involves the relationship between an attribute and stereotyping. When individual is stigmatized, that person is likely to feel embarrassed, alienated, shameful and angry (Link, Yang, Phelan \& Colllins, 2004). Stigmatisation of mentally retarded learners is fuelled by modified labelling theory. According to Mukolo, Heflinger and Wallston (2010) modified labelling theory emanates from relations in society. According to this theory, powerful groups in society tend to impose negative and stereotypical labels to those they perceive as undesirable, and subsequently devalue and discriminate. At school, learners with mental retardation are stigmatized, rejected, teased and often exposed to various forms of abuse (Fishbein, 2014). As a result, their self- esteem diminish and often interferes with their life's goals and quality of life. In most cases, they get less attention, less stimulation, less education, less medical care and sometimes less nourishment than other children (Corrigan \& Watson, 2004; Munyi, 2012).

One of the reasons the mentally retarded children experience stigma and discrimination it is because of the perceptions prevailing in societies that they are violent and deviant. To show how complex is their situation, Todd (2005) found that between 2003 and 2009, about 170 rape survivors with mental retardation were referred for assessment by the courts to the Free State Psychiatric Complex (FSPC) in Bloemfontein, South Africa, since they were perceived as sexually possessing an uncontrollable sexual desires and perverted sexual habits (Calitz, 2011). According to Watson, Corrigan, Larson and Sells (2007) such perceptions refer to what is called -stereotypes. Stereotypes are described as beliefs that associate groups of people with certain traits, which can be bad or good. Prejudice, discrimination and stereotypes are the ABCs of intergroup relationships and interwoven. The Affective component is prejudice, the Behavioural component is discrimination, and the Cognitive component is stereotyping (Baumister \& Bushman, 2011). The danger of such stigma builds self-hate and harbouring of hostility. The society perceive them as homicidal maniacs, responsible for their illnesses and having weaker characters, which results in building diminished self-efficacy which may lead to not pursuing life opportunities and goals (Corrigan \& Watson, 2004; Watson et al., 2007). Drawing from Bandura's social cognitive theory, when children lack self-efficacy (beliefs about their own abilities and potential), they may drop out of school prematurely owing to a lack of extrinsic motivation ( Louw \& Louw, 2007).

\subsubsection{Sexual abuse}

$90 \%$ of the mentally challenged children experience sexual abuse at some point in their lives (Groce, Rohleder, Eide, MacLachlan, Mall \& Swartz, 2013). They are the victims of (1) rape by the bus-drivers who transport them to and from school (Helander, 2004), (2) neglect or maltreatment by their educators (Groce \& Trasi, 2004) and (3) physical abuse in residential care or by their own family members (Shumba \& Abosi, 2011). Child sexual abuse encompasses a wide spectrum of acts and from legal point of view, is defined by Criminal Law (Sexual Offences and Related Matters) Amendment Act 32 of 2007, as a violation of human rights by compelling a minor (a person below age 18) to witness pornography or to be involved in physical contact with another person performing oral sex or in sexual act (e.g. masturbation, vaginal or anal penetration) (South Africa, 2007). Despite this definition, mentally retarded children still face enormous challenges because of limited opportunities for sexuality education. United Nations (2006) calls for support in favour of the mentally challenged children regarding HIVIAIDS information and services in the same way as all other members of society so that perpetrators may be arrested. Phasha (2013) found that communication barriers contribute towards not receiving reports of sexual abuse since the language used to name sexual parts are wrong. For example, in her qualitative study conducted with two professional social workers responsible for two schools for the mentally challenged in the informal settlements near Johannesburg, she found that convincing evidence to prosecute the alleged perpetrators often lack from the abused children. Below is the explanation given by the social workers as to why the court dismisses charges of sexual abuse:

\footnotetext{
"The language used by these learners is difficult for prosecutors to understand, so their cases end up nowhere. They do not use proper names for body parts. They use terms such as banana or dummy for men's private parts. So the courts dismiss their cases for struggling to get appropriate and convincing evidence"
}

In a qualitative study carried out in Botswana, Shumba and Abosi (2011) found that educators were reported to be central in perpetrating sexual abuse. By virtue of their roles as loco-parentis and powers bestowed on them, they would let mentally challenged girls do their household chores (e.g. cleaning) after school hours and rape them. Such educators 
deserve to be struck off the roll should they be found sexually abusing children since there is nowhere in the Code of Ethics, educators are permissible to let children do the household chores.

\subsection{Sexual abuse of mentally challenged children}

\subsubsection{Family structure and fear of victimisation by perpetrators}

Sexual exploitation of the mentally retarded children, dysfunctional families and orphanhood are profoundly intertwined. Disrupted family function could be related to child sexual abuse especially when families are characterized by domestic violence, parents undergo separation or die, leaving children as orphans. Orphans refer to children below the age of 18 years whose parents have died (Freeman \& Nkomo, 2006). Orphans also refer to children who have been abandoned by their parents (Henderson, 2006). Germann (2005) is of the opinion that orphan-hood is usually seen as a social distress as it is associated with psychological and emotional trauma.

Social- disorganization theory by Shaw and McKay as illustrated in figure 1, asserts that when the family members or the residents of the same neighbourhood lack the ability to unite to achieve a common goal, to reduce crime and rape, such community is most likely to suffer psychologically and socially (Wilcox, Land \& Hunt, 2003). For example, Chitereka (2010) found that when the perpetrator of sexual abuse is the father, normally it becomes a challenge for the family members to press charges especially if they are financially dependent on him. To avoid being stigmatized by members of the community, members of the family keeps it as a secret although sexual exploitation of the mentally retarded becomes continual. Montes and Halterman (2007) found that this cloak of secrecy tends to develop depression and neurotic tendency needs on the mother of the sexually abused child. In turn, the mother may repress the frustration, betrayal and anger by resorting to drugs and alcohol abuse (which will now create a comfortable ground for others to sexually abuse) the child because of negligence.

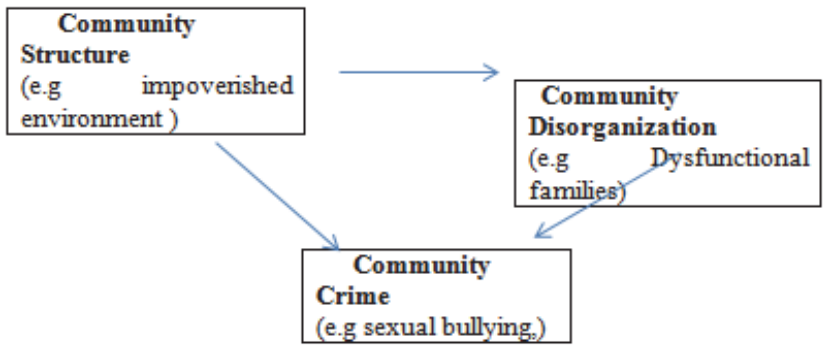

Figure 1: Shaw and McKay's model of social disorganization

\subsubsection{Sex-education}

Children with mental retardation often lack the skills to make well-informed decision regarding sexuality issues. They are often neglected, turned away or not invited to HIVIAIDS forums because of the assumption that they are not sexually active (UNAIDS, 2004 ). They are at high risk for sexual exploitation by their neighbours or caregivers since they long for affection and warmth as opposed to isolation and social exclusion (Swango- Wilson, 2011). Even when sexual abuse is accompanied by incentives or bribery, which could be better explained by social exchange theory, majority of mentally challenged children are less likely to report the incidents of abuse (Withers \& Morris, 2012). In Zimbabwe, Tikiwa (2006) found that the increased reports of sexual abuse of mentally challenged children is influenced by superstitions and myths that people with disabilities are free from HIVIAIDS, the question that remains is how do the mentally challenged children negotiate safe sex? This implies that mentally challenged children may be susceptible to sexually transmitted infections such as gonorrhoea, syphilis, Chlamydia and HIVIAIDS. Furthermore, if they are raised in families where parents are not supportive and knowledgeable about family planning, mentally challenged girls may be made pregnant and left without knowing who the father is, especially when not using birth-control methods. Because there is still little information available about contraceptives among mentally adolescent females in African countries, the only literature which supports the concern above was found in the research work conducted abroad, more than 30 years ago by Chamberlain, Rauh, Passer, McGrath and Burket (1984) who found the rate of incest and exploitation of mentally retarded adolescents to be alarming. 


\subsubsection{Poverty}

Growing up in poverty-stricken environment such as rural areas or informal settlements could be a disadvantage for parents of the mentally challenged children in terms of reporting sexual abuse to the police owing to the travelling costs to be incurred, poorly constructed roads and unnumbered houses in case of calling professionals (e.g social workers) or ambulances to help the victims (Phasha, 2013). In Lurwaziyo village near Willowvale (Eastern Cape Province), Sowetan newspaper (May, 2012) got report of rape of a 15 year old mentally retarded girl by a 20 year-old man in a stock kraal after the grandmother alerted the police. Despite the perpetrator being found busy raping the girl by the grandmother, in most cases the judicial system seems not to stand for the victims since majority of these vulnerable have language deficits to express their ordeal.

On the other hand, reports from African countries reveal that even parents who regarded their intellectually impaired children as unworthy were found to be selling their deaf daughters to brothel operators (World Bank, 2003). Consistent with this inhumane practice, Groce, Rohleder, Eide, MacLachlan, Mall and Swartz (2013) found that in South Africa, Uganda and Zimbabwe, the rate of HIVIAIDS among the mentally retarded girls is at alarming proportion because they are unable to negotiate safe sex. The sad part of sexual abuse of this marginalised group is that once they are infected with HIVIAIDS, it is noticed when it full- blown and die before receiving diagnosis and treatment due to lack of communication skills, support network and education (Hanass-Hancock, 2009).

\subsubsection{Drugs}

The mentally retarded children are susceptible to rape and other atrocities especially when they are under the influence of drugs. According to Jewkes, Nduna, Shai and Dunkle (2012), rape refers to any sexual act, attempt to obtain a sexual act, unwanted sexual comments or advances, or acts to traffic, or otherwise directed against any individual's sexuality, using coercion (i.e., psychological intimidation, physical force, or threats of harm), by any person regardless of relationship to the victim, in any setting, including home and work. In Soweto, Gauteng Province, South Africa, Sowetan newspaper (03 May 2012) reported that a 17 year-old adolescent male got raped by a woman (aged 26) and a teenage girl (aged 17) after being drugged.

\subsubsection{Cultural practices and traditions}

Cultural aspects such as polygamy and gender imbalances fuel sexual abuse of the mentally challenged children. Communities which practice "isithembu"- (i.e. marrying of more than one wife), tend to put the health of the intellectually impaired adolescent females at risk of contracting HIVIAIDS because they are seen as possessing luck, though often unworthy (Hanass-Hancock, 2009; Phasha \& Myaka (2009)). In one village from KwaZulu- Natal, Phasha and Myaka (2009) found that traditional leaders ordered their male clients to abduct mentally retarded girls in order to be financially rich and be respected in the community. Abduction in Zulu language is referred to "ukuthwala" and it means to carry take a girl forcibly to the man's home to signify the intention of marriage (Makho, 2009). According to Hanass-Hancock (2009), girls with hearing impairments become the soft targets for ukuthwala since they cannot shout for help or report about the sexual abuse, leaving them with posttraumatic stress disorder, lack of sleep and eating disorders.

\subsubsection{Death}

Majority of mentally retarded children face brutal killings from their perpetrators once they have been sexually abused. In Kaloleni village, Kenya, Oni (2014) reported the death of a mentally ill girl who was strangled and dumped on the river banks of River Voi, in 2013. A Human Right Watch Report (2001) found that some of the reasons which contribute to the deaths of the mentally challenged children is attributable to many factors, including isolated locations of the institutions and lack of oversight mechanism that would allow the visitors or staff members to witness the ordeal.

In the next paragraph, the effects of sexual abuse on the mentally retarded children will be discussed.

\subsection{Effects of sexual abuse}

\subsubsection{Psychological and behavioural effects}

Sexual abuse is detrimental to and may bear harmful results. Psychologically, the mentally challenged child may feel 
depressed, develop shame and guilt, loss of trust and irrational fears since their self-esteem are tarnished. Behaviourally, the tendency to be socially withdrawn, self-injurious, non-compliant and to be sexually promiscuous is common (NolenHoeksema, 2008). The delay for therapy may further exposes mentally retarded children to psychomatic symptoms such as development of seizures, stomach-aches, headaches, insomnia ( lack of sleep) and restlessness (Sobsey, 2003). It is therefore imperative to look for the following physical signs when the mentally challenged children have been or are being sexually abused:

- Unexplained pregnancy (in the case of a girl)

- Genital discomfort leading to sexual provocation

- Bruises and bleeding in the genital areas

- Complaint of piles (as this could be the sign of anal penetration)

\subsection{Way-forward}

- Educators ought to have positive attitudes towards the mentally challenged learners and develop tolerance since this group of children progress slowly academically.

- As raised by Pillay (2012), the judiciary system should take into account the cognitive limitations of the mentally challenged children when detailing their sexual ordeal than to be intimidated during crossexamination by the perpetrator's legal representative.

- According to Palmer, Wehmeyer, Davies and Stock (2012) children with intellectual disabilities can be empowered provided a constellation of support is in place (e.g. family members, community and educators) to enhance independence, and modify the environment to ensure access to learning.

- Although these children may have language deficits, social work programmes should not be insufficient in addressing sexual abuse (Sossou \& Yogtiba, 2009) because within the framework of African Charter on the Rights and Welfare of the Child (ACRWC) which was endorsed on the 29 November 1999, children deserve to grow up in a family setting characterized by love, happiness and nurturance (Lloyd, 2002).

\section{References}

Baumeister RF, Bushman BJ 2011. Social Psychology \& Human Nature. (2nd Edition.). San Francisco, C.A: Cengage.

Burns, J. K. (2011). The mental health gap in South Africa-a human rights issue. The Equal Rights Review 2011; 6: 99, 113.

Calitz, F. J. (2011). Psycho-legal challenges facing the mentally retarded rape victim. South African Journal of Psychiatry, 17(3), 66-72.

Chamberlain, A., Rauh, J., Passer, A., McGrath, M., \& Burket, R. (1984). Issues in fertility control for mentally retarded female adolescents: I. Sexual activity, sexual abuse, and contraception. Pediatrics, 73(4), 445-450.

Chitereka, C. (2010). "Child Sexual Abuse in Zimbabwe: The Agenda for Social Workers." Asia Pacific Journal of Social Work and Development, 20(1), 29-40.

Corrigan, P. W., \& Watson, A. C. (2004). At issue: Stop the stigma: call mental illness a brain disease. Schizophrenia Bulletin, 30(3), 477.

Donohue, D. K., Bornman, J., \& Granlund, M. (2014). Examining the rights of children with intellectual disability in South Africa: Children's perspectives. Journal of Intellectual and Developmental Disability, 39(1), 55-64.

Driedger, D. (Ed.). (1991). Disabled people in international development. Coalition of Provincial Organizations of the Handicapped.

Fishbein, H. D. (2014). Peer prejudice and discrimination: The origins of prejudice.(2nd ed.). Routledge : New York.

Freeman, M., \& Nkomo, N. (2006). Guardianship of orphans and vulnerable children. A survey of current and prospective South African caregivers. Aids care, 18(4), 302-310.

Frumkin, I.B. (2003). Mental retardation and the law: Common misconceptions, Cornerstone, 25, \#2, Washington, DC: National Legal Aid and Defender Association.

Germann, S. E. (2005). An exploratory study of quality of life and coping strategies of orphans living in child-headed households in the high HIV/AIDS prevalent city of Bulawayo, Zimbabwe . (Doctoral dissertation). University of South Africa: Pretoria.

Groce, N. E., Rohleder, P., Eide, A. H., MacLachlan, M., Mall, S., \& Swartz, L. (2013). HIV issues and people with disabilities: a review and agenda for research. Social Science \& Medicine, 77, 31-40.

Groce, N. \& Trasi,R. (2004): "Rape of Individuals With Disability: AIDS and the Folk Belief of Virgin Cleansing," The Lancet 363 pp. 1663-1664.

Hanass-Hancock, J. (2009). Disability and HIVIAIDS-a systematic review of literature on Africa. Journal of the International AIDS Society, 12(1), 34 .

Helander, E. A. (2004). Abuse and neglect of persons in residential institutions and the international law Part II. Revista Romana de Bioetica, 2(1).

Henderson, P. C. (2006). South African AIDS Orphans Examining assumptions around vulnerability from the perspective of rural children 
and youth. Childhood, 13(3), 303-327.

Human Rights Watch. 2001. Easy Targets: Violence against Children Worldwide. New York: Human Rights Watch.

Hunt, P., \& Mesquita, J. (2006). Mental disabilities and the human right to the highest attainable standard of health. Human Rights Quarterly, 28(2), 332-356.

International Disability and Development Consortium (IDDC). (2012). IDDC policy briefing on HIV \& AIDS and disability. IDDC HIV \& AIDS and Disability Task Group. http://www.iddcconsortium.net/joomla/images/IDDCdocuments/2012_jun_iddc_policy_briefing_ hiv_aids_disability_final.pdf.

Jewkes, R., Nduna, M., Shai, N. J., \& Dunkle, K. (2012). Prospective study of rape perpetration by young South African men: incidence \& risk factors. PloS one, 7(5), e38210.

King, G., Zwaigenbaum, L., Bates, A., Baxter, D., \& Rosenbaum, P. (2012). Parent views of the positive contributions of elementary and high school-aged children with autism spectrum disorders and Down syndrome. Child: care, health and development, 38(6), 817828.

Leinonen, J.A., Solantaus, T.S., \& Punamaki, R.L (2003). Parent mental health and children's mental health adjustment: the quality of marital interaction and parenting as mediating factors. Journal of child psychology and psychiatry. Volume 44: 227-241.

Lloyd, A. (2002). ' Evolution of the African Charter on the Rights and Welfare of the Child and the African Committee of Experts: Raising the Gaunlet'. International Journal of Children's Rights, Vol 10(2), 179-19.

Louw, D. \& Louw, A. (2007). Child and Adolescent Development. Bloemfontein: University of the Free- State.

Makho, N. (2009). Bride Abduction in KwaZulu Natal Schools \& Its Effects on Education, Agenda: Empowering women for gender equity. Masters in Gender Studies.

Montes, G., \& Halterman, J.S. (2007). Psychological functioning and coping among mothers of children with autism. A population-based study. Pediatrics,119. e1040- e1046. doi:1542/peds. 2006-2819.

Mukolo, A., Heflinger, C.A., \& Wallston, K. (2010). The stigma of childhood mental disorders: A conceptual framework. Journal of the American Academy of Child and Adolescent Psychiatry.

Munyi, C. W. (2012). Past and present perceptions towards disability: A historical perspective. Disability Studies Quarterly, 32(2).

Noleen- Hoeksema, S. (2008). Abnormal Psychology. Media \& Research Update. (4th edition.). McGram- Hill Higher Education: Boston.

Passer, M. W., Smith, R. E., Holt, N., Bremner, A., Sutherland, E., \& Vliek, M. (2009). Psychology: The science of Mind and Behaviour. McGraw- Hill: London.

Oni, K.. (2014). Mentally Retarded Girl Raped And Murdered. www.naij.com/17748.html

Palmer, S. B., Wehmeyer, M. L., Davies, D. K., \& Stock, S. E. (2012). Family members' reports of the technology use of family members with intellectual and developmental disabilities. Journal of Intellectual Disability Research, 56(4), 402-414.

Papalia, D.E., Olds, S.W., \& Feldman, R.D. (2009). Human development. McGraw-Hill: New York .

Petersen, I., Swartz, L., Bhana, A., \& Flisher, A. J. (2010). Mental health promotion initiatives for children and youth in contexts of poverty: the case of South Africa. Health promotion international, daq026.

Phasha, T.N. (2013). Influences on Under Reporting of Sexual Abuse of Teenagers with Intellectual Disability: Results and Implications of a South African Study. Journal of Psychology in Africa, 23(4), 625-629.

Phasha, N., \& Myaka, L. (2009). A custom distorted: Beliefs about sexual abuse involving teenagers with intellectual disability at a rural setting in South Africa. Unpublished paper. University of Johannesburg.

Pillay, A. L. (2012). The rape survivor with an intellectual disability vs. the court. South African Journal of Psychology, 42(3), 312-322.

Plagerson, S., Patel, V., Harpham, T., Kielmann, K., \& Mathee, A. (2011). Does money matter for mental health? Evidence from the Child Support Grants in Johannesburg, South Africa. Global public health, 6(7), 760-776.

Sobsey, D. (2003). Violence and disabled children: One-in-ten. New York: Rehabilitation International, 24, 2-4.

Sossou, M. A., \& Yogtiba, J. A. (2009). Abuse of children in West Africa: implications for social work education and practice. British Journal of Social Work, 39(7), 1218-1234

Swango-Wilson, A. (2011). Meaningful sex education programs for individuals with intellectual/developmental disabilities. Sexuality and Disability, 29(2), 113-118.

Tikiwa, S. (2006, September 3). Disabled women under threat of sexual abuse. Zimbabwe Sunday Mail, p. 2.

Todd, R.M.J. (2005). Sexual Abuse Victim Empowerment Programme: An archiaval study assessing the relationship between demographics and level of intellectual functioning. (Unpublished Master's dissertation). Stellenbosch University: Stellenbosch.

UNAIDS/UNICEF/USAID. (2004). Children on the Brink: A Joint Report of New Orphan Estimates and a Framework for Action. New York: UNICEF.

United Nations (2006). Conventions on the rights of persons with disabilities. http://www.un.org/disabilities/defaults.asp? Id=259 Accessed 21.04.11

Watson, A. C., Corrigan, P., Larson, J. E., \& Sells, M. (2007). Self-stigma in people with mental illness. Schizophrenia bulletin, 33(6), 1312-1318.

Wilcox, P., Land, K.C., \& Hunt, S.A. (2003). Criminal circumstance: A dynamic multi-contextual criminal opportunity theory. Hawthorne : Transaction Publishers.

Withers, P., \& Morris, J. (2012). Sexual exploitation of people with intellectual disabilities. Clinical Psychology and People with Intellectual Disabilities, 273-92.

World Bank. (2003). Adolescents and Youth with Disabilities: Issues and Challenges. Washington, DC. 